\title{
Immunobiological Activity of Synthetically Prepared Immunodominant Galactomannosides Structurally Mimicking Aspergillus Galactomannan
}

OPEN ACCESS

Edited by: Uday Kishore,

Brunel University London, United Kingdom

Reviewed by:

Lalit Kumar Dubey, University of Lausanne, Switzerland

Taruna Madan, National Institute for Research in Reproductive Health, India

${ }^{*}$ Correspondence: Ema Paulovičová ema.paulovicova@savba.sk; Nikolay E. Nifantiev nen@ioc.ac.ru

Specialty section: This article was submitted to Molecular Innate Immunity, a section of the journal

Frontiers in Immunology

Received: 16 June 2017 Accepted: 25 September 2017 Published: 13 October 2017

Citation:

Paulovičová E, Paulovičová L, Hrubiško M, Krylov VB, Argunov DA and Nifantiev NE (2017) Immunobiological Activity of Synthetically Prepared Immunodominant

Galactomannosides Structurally Mimicking Aspergillus Galactomannan.

Front. Immunol. 8:1273. doi: 10.3389/fimmu.2017.01273

\author{
Ema Paulovičová1*, Lucia Paulovičová', Martin Hrubiško², Vadim B. Krylov³, \\ Dmitry A. Argunov ${ }^{3}$ and Nikolay E. Nifantiev ${ }^{3 *}$
}

${ }^{1}$ Cell Culture Laboratory, Department of Immunochemistry of Glycoconjugates, Center for Glycomics, Institute of Chemistry, Slovak Academy of Sciences, Bratislava, Slovakia, ${ }^{2}$ Department of Clinical Immunology and Allergy, Oncology Institute of St. Elisabeth, Bratislava, Slovakia, ${ }^{3}$ Laboratory of Glycoconjugate Chemistry, N.D. Zelinsky Institute of Organic Chemistry, Russian Academy of Sciences, Moscow, Russia

The study is oriented at the in vitro evaluation of the immunobiological activity and efficacy of synthetically prepared isomeric pentasaccharides representing fragments of Aspergillus fumigatus cell-wall galactomannan and containing $\beta-(1 \rightarrow 5)$-linked tetragalactofuranoside chain attached to O-6 (GM-1) or O-3 (GM-2) of a spacer-armed mannopyranoside residue. These compounds were studied as biotinylated conjugates which both demonstrated immunomodulatory activities on the RAW 264.7 cell line murine macrophages as in vitro innate immunity cell model. Immunobiological studies revealed time- and concentration-dependent efficient immunomodulation. The proliferation of RAW 264.7 macrophages was induced at higher concentration (100 $\mu \mathrm{g} / \mathrm{mL})$ of studied glycoconjugates and longer exposure (48 h), with more pronounced efficacy for GM-1. The increase of proliferation followed the previous increase of IL-2 production. The cytokine profile of the macrophages treated with the glycoconjugates was predominantly pro-inflammatory Th1 type with significant increase of TNF $\alpha$, IL-6, and IL-12 release for both glycoconjugates. The RAW 264.7 macrophages production of free radicals was not significantly affected by glycoconjugates stimulation. The phagocytic activity of RAW 264.7 cells was reduced following GM-1 treatment and was significantly increased after $24 \mathrm{~h}$ stimulation with $\mathbf{G M - 2}$, contrary to $48 \mathrm{~h}$ stimulation. Moreover, the synthetically prepared galactomannoside derivatives have been evaluated as efficient serodiagnostic antigens recognized by specific Ig isotypes, and significant presence of specific IgM antibodies in serum of patients suffering from vulvovaginitis was observed.

Keywords: Aspergillus, Candida, galactomannan, mannan, RAW 264.7, cytokines

\section{INTRODUCTION}

Throughout the past decades, the incidence of opportunistic systemic fungal infections has a significant rise due to increased numbers of immunocompromised adult and pediatric individuals. Candida species are the most common ubiquitous medically important opportunistic fungi followed by Aspergillus species (1-3). Invasive aspergillosis is the second most frequent systemic fungal 
infection with increasing incidence over the last 20 years (4). Aspergillus spp. principally affect the lungs causing the four main Aspergillus-related syndromes: (i) allergic bronchopulmonary aspergillosis, (ii) chronic necrotizing Aspergillus pneumonia (also termed chronic necrotizing pulmonary aspergillosis), (iii) aspergilloma, and (iv) invasive aspergillosis. Hematogenous dissemination of Aspergillus beyond the lungs has been documented in patients who are severely immunocompromised (5). Within an 1 year period (from 2016 until present), the 1.47-fold increase in Aspergillus spp. in clinical isolates from upper airways and 1.8-fold increase in Aspergillus spp. clinical isolates from the lower respiratory tract have been documented. Moreover, the cutaneous aspergilli isolates increased 2.15 times within this period (raw data were obtained and analyzed with permission of MEDIREX Inc., HPL Mycology Labs., Slovakia).

Invasive aspergillosis has become the major cause of morbidity and mortality in immunocompromised patients with mortality rates as high as $90 \%$. Almost $61 \%$ of patients with invasive aspergillosis have an underlying hematologic disease or have undergone bone marrow transplantation (6). Risk factors for the development of invasive aspergillosis include prolonged or repeated episodes of severe neutropenia, transplantation of solid organs or receipt of an allogenic stem cell transplant, grade III or IV graft-vs.-host disease, prolonged use of corticosteroid therapy, treatment with T-cell immunosuppressants, and inherited severe immunodeficiency $(7-12)$. Etiological agent of more than $90 \%$ of invasive mycoses caused by Aspergilli is an Aspergillus fumigatus (A. fumigatus) (13). The treatment of invasive fungal infections failed in nearly $50 \%$ cases of invasive aspergillosis (14). Furthermore, resistant Aspergillus infections are frequently encountered in the antifungal drug-naïve patient as a result of increasing incidence of environmental $A$. fumigatus isolates harboring azole resistance mechanisms. In vivo selection of acquired resistance during medical treatment is increasingly more accounted in the patients with chronic forms of aspergillosis on the long-term azole treatment (15).

The anti-Aspergillus host immune defense is mediated by a complex of responses of the innate immune system phagocytic cells, resident alveolar macrophages, which ingest and kill Aspergillus conidia. Next, polymorphonuclear leukocytes destroy germinating Aspergillus hyphae, which escaped from macrophages. Neutrophils participate in the adaptive $\mathrm{T}$ helper cell response that in turn modulates antifungal activity, enhancing the phagocyte effector cell function (16). There are intensive efforts to design the effective model of subcellular fungal vaccines for either active or passive immunization in humans based on the dominant fungal cell-wall derived moieties (17-21).

In the vaccine model, different preparations of $A$. fumigatus antigens accelerated expansion of various CD4 T-cell subsets (22). The vaccinating potential of different Aspergillus antigens against invasive pulmonary aspergillosis, using antigen with the immunoadjuvant murine $\mathrm{CpG}$ oligodeoxynucleotide (CpG/Ag model) and dendritic cells model has been also studied (22).

Generally, the A. fumigatus cell wall is composed of a fibrillar skeleton made of $\beta$ - $(1 \rightarrow 3)$-glucan chains with 3,6-branches bound to chitin, galactomannan, and $\beta-(1 \rightarrow 3) /(1 \rightarrow 4)$-glucan, embedded in an amorphous alkali-soluble cement mainly composed of $\alpha$-(1 $\rightarrow 3)$-glucan and galactose polymers: galactomannan and galactosaminogalactan $(23,24)$.

Galactomannan is a hetero-polysaccharide composed of a mannan core and galactofuransyl side-chain found in the cell wall primarily of mold-like fungi especially in Aspergillus spp. and Penicillium spp. but is also found in other species of fungi. The backbone chain of Aspergillus galactomannan comprises the $(1 \rightarrow 2) /(1 \rightarrow 6)$-linked $\alpha$-D-mannopyranosyl residues substituted at O-3 or O- 6 by oligo- $\beta$-D-galactofuranosyl-containing sidechains connected mainly via $(1 \rightarrow 5)$-links. Such $\beta$-D-Galf-bearing chains are regarded as immunodominant epitopes, especially when they are $(1 \rightarrow 5)$-linked $(25,26)$. The immunodominant epitopes are located in tetra- and hexasaccharides containing $\beta$-D-Galf- $(1 \rightarrow 5)-\beta$-Gal terminal groups (27). Kudoh et al. reported the presence of $\beta$-1,6-linked Gal $f$ residues in addition to the $\beta$-1,5-linked Gal $f$ residues in the O-linked and $\mathrm{N}$-linked carbohydrate moieties of the galactomannan from $A$. fumigatus (28). As concerned content, the differences between conidia and hyphae alkali-soluble and insoluble fractions thereof have been reported. The exposition of galactomannan in an alkali-insoluble fraction of conidia has been higher, i.e., 26 vs. $5 \%$ present in hyphae (29).

Herewith, we report for the first time a comparative study of the immunobiological activity and immunomodulating efficacy of synthetically prepared pentasaccharide derivatives GM-1 and GM-2 (Figure 1), whose structure mimics the corresponding fragments of $A$. fumigatus galactomannan bearing $\beta$ - $(1 \rightarrow 5)$-linked tetragalactofuranoside chain attached to $\mathrm{O}-3$ or O-6 of the mannopyranoside residue. This study is focused on the assessment of proliferative activities, stimulated release of Th1and Th17 interleukins and growth factors, phagocytosis, free radicals release, expression of CD11b and F4/80 following RAW 264.7 macrophages GM-1 and GM-2 exposure. The evaluation of synthetically prepared oligosaccharide conjugates structurally related to $A$. fumigatus galactomannan as serodiagnostic immunogens for in vitro diagnostics of mycosis has been studied.

\section{MATERIALS AND METHODS}

\section{Synthesis of Biotinylated Glycoconjugates GM-1 and GM-2}

Glycoconjugates GM-1 and GM-2 were prepared by the biotinylation of parent ligands (30-32) according to the previously described (33) biotinylation protocol.

\section{Cell Culture and Exposition}

Stock solution and individual glycoconjugate doses were prepared aseptically using pre-sterilized disposable plasticwares and apyrogenic, sterile aqua pro injectione (Fresenius, Kabi Italia S.r.l., Verona). The solutions were filtered using a syringe with a $0.2-\mu \mathrm{m}$ filter (Q-Max ${ }^{\circledR}$ Syringe filter) under sterile laminar flow conditions (Biohazard II, Esco). The safety cabinet was wiped down with $70 \%$ ethanol p.a. and sterilized with a germicidal UV lamp for $30 \mathrm{~min}$ before each experiment. The 


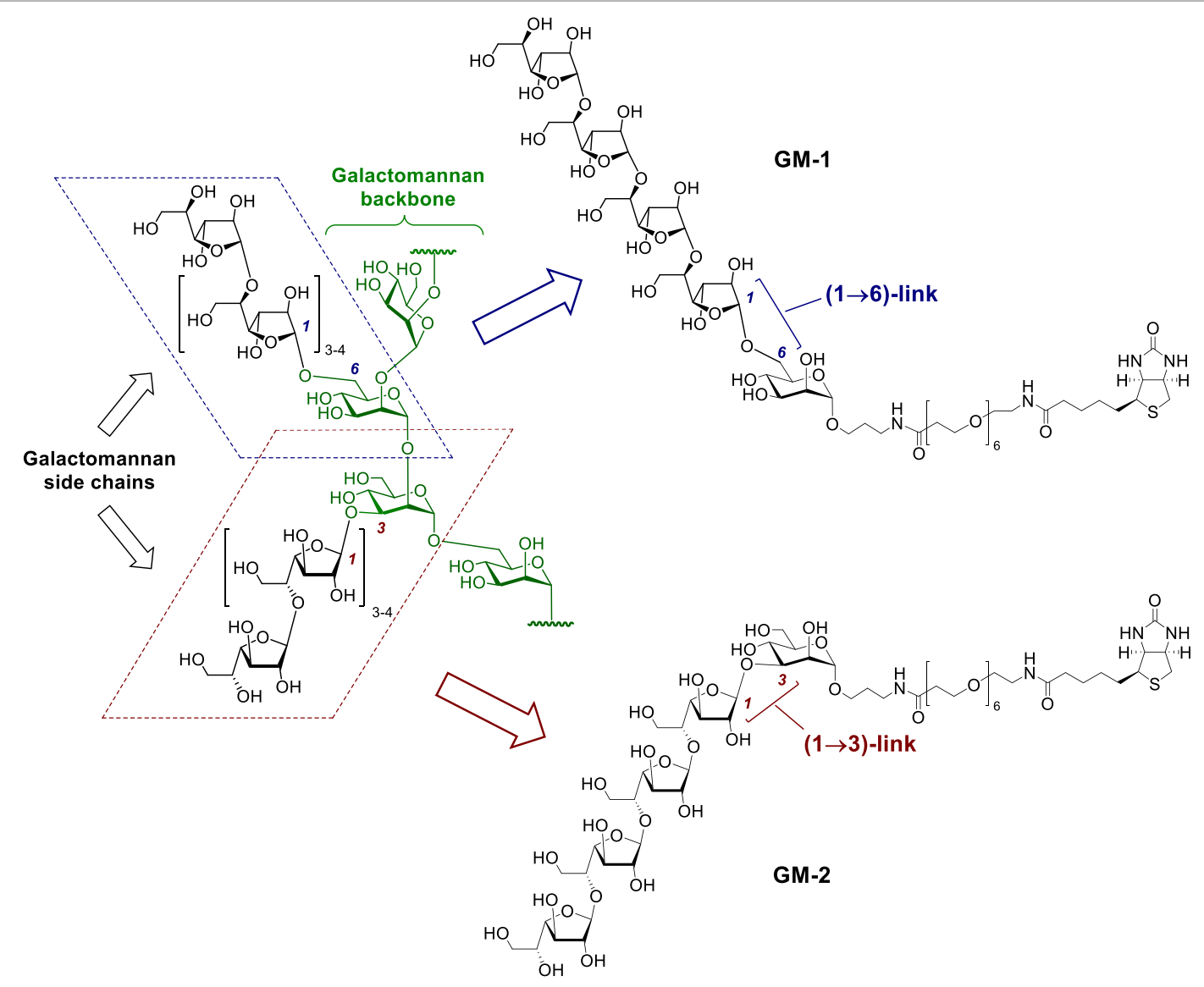

FIGURE 1 | Hypothetical structure of the galactomannan secreted by A. fumigatus (GM-native) (25) and synthetic biotinylated probes GM-1 and GM-2 representing its $(1 \rightarrow 6)$ - and $(1 \rightarrow 3)$-linked epitopes.

stock solution has been assayed with an EndoLISA ${ }^{\circledR}$ enzymelinked immunosorbent assay (ELISA)-based Endotoxin Detection Assay (Hyglos) and measured with a Cytation 5 Imager Multi-Mode Reader (BioTek, USA) to ascertain endotoxin-free conditions.

Cell line murine macrophages RAW 264.7 (ATCC ${ }^{\circledR} \mathrm{TIB}-71^{\mathrm{TM}}$, ATCC, UK) were cultured in complete Dulbecco's Modified Eagle Medium for $24 \mathrm{~h}$ at $37^{\circ} \mathrm{C}$ in a $5 \% \mathrm{CO}_{2}$ atmosphere and $90-100 \%$ relative humidity until approx $80 \%$ confluency. Cell viability was assayed with the Trypan blue dye exclusion method using a TC20 $20^{\mathrm{TM}}$ automated cell counter (Bio-Rad Laboratories, Inc., USA). The starting inocula of $1 \times 10^{5}$ cells $/ \mathrm{mL} /$ well (93.6\% viable cells) were seeded in a 24 -well cell culture plate (Sigma-Aldrich, USA) and exposed to 10 and $100 \mu$ g per well of GM-1 and GM-2 conjugates, respectively, to include two different concentrations with diverse stimulatory capabilities. Concanavalin A (Con A, $10 \mu \mathrm{g} / \mathrm{mL}$, Sigma-Aldrich, St Louis, MO, USA), phytohemagglutinin (PHA, $10 \mu \mathrm{g} / \mathrm{mL}$, SigmaAldrich, St Louis, MO, USA) and pokeweed mitogen $(1 \mu \mathrm{g} /$ $\mathrm{mL}$, Sigma-Aldrich, St Louis, MO, USA) were used as positive controls.

In vitro exposition was performed for 3,24 , and $48 \mathrm{~h}$, respectively. Morphological characteristics and viability were controlled ahead of flowcytometric evaluation. The exposed cells were subjected to immunocytometric determination of phagocytic activity and phenotyping immediately following cell separation by centrifugation. The cell culture media were stored at $-20^{\circ} \mathrm{C}$ until further use.

\section{Proliferation and Cytotoxicity}

The impact of GM-1 and GM-2 conjugates on RAW 264.7 cells' proliferation and glycoconjugates' potential cytotoxicity was evaluated by the bioluminescent measurement of adenosine triphosphate (ATP), marker of metabolically active cells levels, using the ViaLight ${ }^{\mathrm{TM}}$ plus kit (Lonza, USA) according to the manufacturer's instructions. The intensity of emitted light was measured with a Cytation 5 Cell Imaging Multi-Mode Reader (BioTek Instruments, Inc., USA). Light emission expressed as relative light units was recorded continuously for $1 \mathrm{~s}$ and evaluated on the basis of peak values. The proliferation of unstimulated cells was considered to be the baseline. The proliferation index was calculated by the ratio between the induced proliferation (stimulated cells) and the baseline (unstimulated cells) proliferation. Hence, the proliferation index of negative control, i.e., unstimulated cells, is equal to one. 


\section{Determination of Interleukins and Growth Factors}

The levels of interleukins and growth factors in cell culture supernates mediated by the exposure with glycoconjugates GM-1 and GM-2, respectively, were assayed with Quantikine ELISA ${ }^{\circledR}$ Mouse M-CSF [Cat\#MMC00, R\&D, USA, minimum detectable dose $(\mathrm{MDD})<5 \mathrm{pg} / \mathrm{mL}$, Platinum ELISAs ${ }^{\circledR}:$ Mouse IL-12 (p70) (Cat\#BMS616, MDD 4 pg/mL), Mouse GM-CSF (Cat\#BMS612, MDD 2 pg/mL), Mouse IL-17(Cat\#BMS6001, MDD 1.6 pg/mL), Mouse IL-2(Cat\#BMS601, MDD $5.3 \mathrm{pg} / \mathrm{mL}$ ), and Mouse IL-6 (Cat\#BMS603/2, MDD $6.5 \mathrm{pg} / \mathrm{mL}$ ); Instant ELISAs ${ }^{\circledR}$ : Mouse IL-1 $\beta$ (Cat\#BMS600/2INST, MDD $3 \mathrm{pg} / \mathrm{mL}$ ), Mouse tumor necrosis factor (TNF)- $\alpha$ (Cat\#BMS607/2INST, MDD $4 \mathrm{pg} / \mathrm{mL}$ ), Mouse IL-10 (Cat\#BMS614INST, MDD $5.28 \mathrm{pg} / \mathrm{mL}$ ), all from Affymetrix e-Bioscience, USA, according to the instructions of the manufacturer.

\section{Determination of Free Radicals}

The cell culture supernates obtained after the treatment of RAW 264.7 cells by glycoconjugates GM-1 and GM-2 were assayed for total content of free radicals (Free radicals kit; SediumR\&D, Czech Republic). The assay is based on the ability of chlorophyllin to transfer electrons due to its electron-rich double-bonds structure. The free radicals media levels were assayed via calibration based on a $\mathrm{Fe}^{2+} / \mathrm{Fe}^{3+}$ reactive shift and were expressed as millimoles $\mathrm{Fe}^{2+} / \mathrm{L}$. The unstimulated cells free radical production was used to determine the baseline value.

\section{Immunocytometry}

The GM-1 and GM-2 conjugates' exposed RAW 264.7 cells were subjected to immunoflow cytometry using a Beckman Coulter FC 500 flow cytometer equipped with a 488-nm argon laser and a $637 \mathrm{~nm}$ HeNe collinear laser and controlled by the CXP software (Beckman Coulter, Fullerton, CA, USA). Gates were set to exclude the debris and damaged cells using forward scatter vs. side scatter dot plot discrimination. The settings were optimized either using proper isotype control (in immunophenotyping assay) or Candida albicans fluorescein isothiocyanate (FITC)-untreated cell culture (in phagocytosis). For each sample fluorescence histograms of 10,000 cells (immunophenotyping) or 5,000 cells (phagocytosis) were generated and analyzed (green fluorescence, 525-nm band-pass filter, FL1 channel). All samples were analyzed in duplicates. The data are expressed as percentage or as a mean of fluorescence intensity.

For immunocytometric assays, GM-1 and GM-2 conjugates exposed RAW 264.7 cells were stained directly with FITCconjugated rat anti-mouse monoclonal antibodies: F4/80 and CD11b (both from eBioscience, Inc., CA, USA). The appropriate antibody isotype-negative controls were used separately to achieve correct gating. The FITC-conjugated monoclonal antibodies $(5 \mu \mathrm{L})$ and $\mathbf{G M}-\mathbf{1}$ and $\mathbf{G M}-\mathbf{2}$ conjugates treated RAW 264.7 cells $(50 \mu \mathrm{L})$ were added to 5 -mL sterile tubes (Beckman Coulter, Fullerton, CA, USA) and incubated for $30 \mathrm{~min}$ in the dark at $4^{\circ} \mathrm{C}$. After this, the samples were evaluated by immunoflowcytometry.

\section{Phagocytosis}

Measurement of phagocytosis, i.e., the ingestion of labeled Candida albicans (C. albicans) cells, took place under controlled conditions, using incubation with (FITC)-labeled C. albicans for $30 \mathrm{~min}$ at $37^{\circ} \mathrm{C}$. Following treatment, the reaction was stopped by placing the samples on ice. Based on the difference between the resulting total amount of phagocyting cells and the amount of phagocyting cells following fluorescence quenching using Trypan Blue, the amounts of adherent extracellular and ingested intracellular Candida cells were determined.

\section{Fluorescence Quenching Cytofluorometric Assay}

The extracellular FITC-fluorescence has been quenched by $0.4 \%$ trypan blue dye (Sigma-Aldrich, USA). Immunocytometric analysis of trypan blue treated RAW 264.7 cells was performed following 30-min cell incubation in dark. Differentiation between attached and ingested C. albicans-FITC labeled cells was performed using the same protocol as previously described.

\section{Study Population}

The serological assays were performed in a patient cohort comprising forty female participans $(38.2 \pm 8.4$ years $)$ with atopy and a history of recurrent vaginal mycosis (Dept. Clin. Immunol. and Allergy). Inhalant allergy was present in $63 \%$ of patients. The exclusion criteria were recent or ongoing antibiotic or immunosuppressive therapy. Candida spp., Aspergillus spp., and Saccharomyces spp. isolated from vaginal $(94.42 \%)$ or cervical (5.58\%) swabs undergone typing and identification (MEDIREX Inc., HPL Mycology Labs., Slovakia). Alyostal ${ }^{\circledR}$ Stallergenes Skin prick test (SPT), including C. albicans allergen (Alyostal R Stallergenes), was performed on the patients' forearm according to the international and national guidelines. SPT was evaluated after 15-20 min and rated as positive if the wheal diameter was $\geq 3 \mathrm{~mm}$ and the negative control was negative.

\section{Control Group}

Sixty-five female blood donors (National Blood Service, Slovak Republic) aged $18-56$ years (average $35.9 \pm 18.6$ ) were enrolled as healthy control subjects.

\section{Sera Samples}

All sera samples have been taken before the onset of antifungal and/or immunomodulative therapy, respectively. The sera samples for the determination of anti-oligogalactomannan and anti-mannan antibodies were collected and immediately stored at $-70^{\circ} \mathrm{C}$ until the further use. The specimens were analyzed retrospectively and the results had no influence on therapeutic decisions.

\section{Determination of Anti-GM-1 and -GM-2 $\operatorname{IgG}$, IgA, and IgM Isotypes}

The ELISA for the determination of IgG, IgA, and IgM sera antibodies specific to studied galactomannosides has been developed by the modification of ELISA anti-Candida II based on C. albicans cell glycan antigens (Biogema, Slovakia). Synthetically prepared biotinylated oligogalactomannans (in $0.2 \mathrm{M}$ TRIS-HCl 
buffer $\mathrm{pH}$ 7.0) were applied onto streptavidin coated microplates (Bioamat, SNC, Italy) $(2 \mu \mathrm{g} / \mathrm{mL}, 200 \mu \mathrm{L} /$ well $)$ for $24 \mathrm{~h}$ at room temperature. After that, the plates were overcoated with $0.05 \mathrm{M}$ carbonate-bicarbonate buffer ( $\mathrm{pH}$ 9.5) with $0.025 \%$ Tween 20 and washed out. The plates were blocked with 1\% BSA in $0.05 \mathrm{M}$ carbonate-bicarbonate buffer. Sera samples have been examined for the GM-1- and GM-2-specific IgG, IgA, and IgM antibodies with peroxidase-labeled anti-human $\operatorname{IgA}, \operatorname{IgG}$, and IgM antibodies (KPL, USA). The plates were developed with 3,3',5,5'-tetramethylbenzidine chromogenic substrate (KemEn-Tec Diagnostics) and scanned at 450/630 nm (Microplate reader MRXII, Dynex, USA). According to the absence of appropriate international standards, the concentrations of different Ig isotypic antibodies were evaluated based on the calibration curve using internal standard, i.e., positive sera pool with an established value of 100 arbitrary units (U). The cut-off values were calculated according to blood donors' IgG/IgM/IgA antiGM-1 and GM-2 sera values (average + 3 SD). The patients' results were expressed as calculated mean \pm SEMs of two independent measurements. Anti-mannan IgG, IgA, and IgM antibodies were assayed as previously described (34).

\section{Ethics}

The research protocol and the study have been approved by the Local Ethical Committee of the Oncology Institute of St. Elisabeth, Bratislava, Slovakia (15.12.2010). Written informed consent to participate in the experimental research study and for blood collection and subsequent laboratory examinations, in accordance with the principles in the Helsinki Declaration, was obtained from each patient prior to study enrollment. All patients were recruited from the outpatient department of the Department of Clinical Immunology and Allergy. Patient's age, disease process, drug history, family history, and clinical signs and symptoms were documented at the first visit of Clinical Immunology and Allergy ambulance as a standard procedure.

\section{Statistical Analysis}

The results of in vitro experiments with patient sera and RAW 264.7 cells were evaluated as mean values \pm SD. Normality of data distribution was evaluated according to Shapiro-Wilk's test at the 0.05 level of significance. Statistical comparison was performed using one-way ANOVA and post hoc Bonferroni's tests. The results were significant if the differences equaled or exceeded the $95 \%$ confidence level $(P<0.05)$. Statistics was performed using the ORIGIN 7.5 PRO software (OriginLab Corporation, Northampton, MA, USA). Pearson's correlation coefficient was used to compare the strength of the relationship between immunobiological variables.

\section{RESULTS}

\section{GM-1 and GM-2 Glycoconjugates Possess the Capability to Increase the Proliferation of Murine Macrophages RAW 264.7}

The effect of pentasaccharide-biotin conjugates GM-1 and GM-2 on the macrophage cell line RAW 264.7 proliferation was monitored by ATP bioluminescence as a marker of cell viability using the ViaLight ${ }^{\mathrm{TM}}$ plus kit. As shown in Figure 2, shorter stimulation periods ( 3 and $24 \mathrm{~h}$ ) of RAW 264.7 cells did not alter the proliferation of macrophages. The 48-h stimulation resulted in a dose-dependent increase in RAW 264.7 proliferation for both tested biotinylated pentasaccharides. Thus, the stimulation with higher concentration of glycoconjugates $(100 \mu \mathrm{g} / \mathrm{mL})$ induced significantly more pronounced increase of RAW 264.7 proliferation (GM-1: 2.97-fold, and GM-2: 2.31-fold) compared

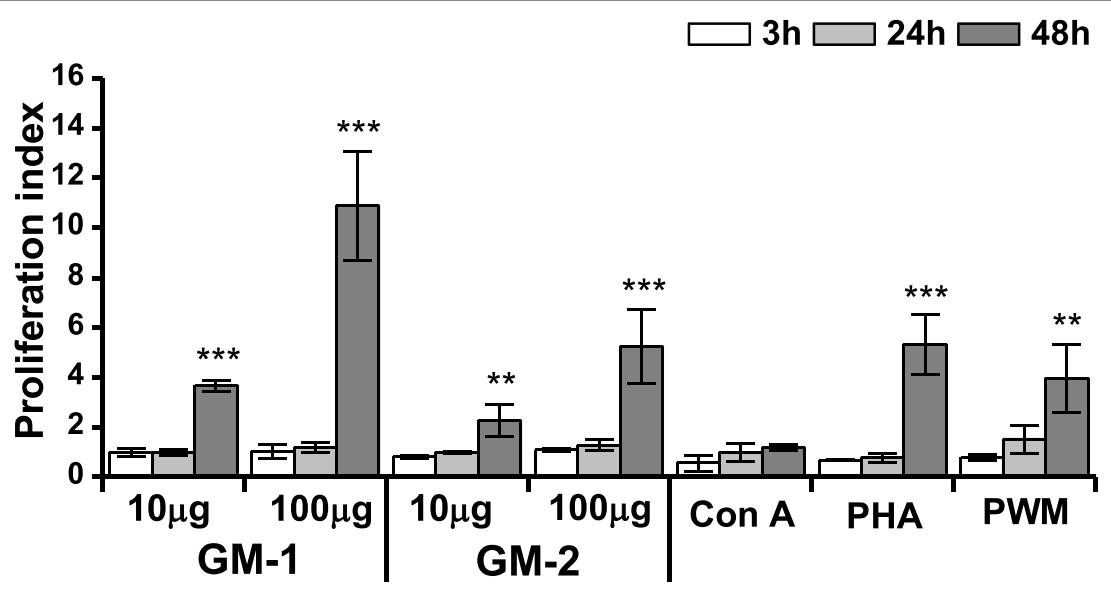

FIGURE 2 | Effect of glycoconjugates GM-1 and GM-2 on proliferation of RAW264.7 macrophages. Cell proliferation was determined by ViaLightTM plus kit. RAW264.7 cells were treated with glycoconjugates GM-1 or GM-2 at concentrations of 10 and $100 \mu \mathrm{g} / \mathrm{mL}$ and with concanavalin A (Con A, $10 \mu \mathrm{g} / \mathrm{mL})$, phytohemagglutinin (PHA, $10 \mu \mathrm{g} / \mathrm{mL}$ ) and pokeweed mitogen (PWM, $1 \mu \mathrm{g} / \mathrm{mL}$ ) as positive controls for 3,24 , and $48 \mathrm{~h}$. Each value presents the mean $\pm \mathrm{SD}$ of proliferation index (ratio of average relative light units (RLU) in the presence of stimulant to average relative light units obtained without stimulation). According to calculation formula of proliferation index, the proliferation index of negative control-untreated cells is equal to one. The statistical significance of differences between stimulated cells and untreated cells using one-way ANOVA and post hoc Bonferroni's tests is expressed: ${ }^{* *}-0.001<P<0.01,{ }^{* *}-P<0.001$. 
to the $10 \mu \mathrm{g} / \mathrm{mL}$ concentration with even higher efficacy for glycoconjugate GM-1 than GM-2.

\section{Cytokine and Free Radical Responses of RAW 264.7 Macrophages In Vitro to GM-1 and GM-2 Glycoconjugates}

Generally, macrophages are tissue-resident professional phagocytes and antigen-presenting cells which differentiate from circulating peripheral blood monocytes. The diversity and plasticity is typical for the cells of the monocyte-macrophage lineage. The initial cross-talk and interaction of macrophages with specific cytokines following antigenic trigger determines their functional phenotype, thus influencing their engagement in processes of the antigen-presentation, phagocytosis, and regulatory functions. Microenvironment in which macrophages are situated provides diverse signals that could influenced the cell proliferation and differentiation, secretion of free radicals and is able to divergently bias the macrophage's phenotype toward highly microbicidal or immunosuppressive macrophages.

The in vitro effect of glycoconjugates GM-1 and GM-2 on RAW 264.7 macrophages cytokines production was analyzed by the determination of pro-inflammatory cytokines TNF $\alpha$, IL- $1 \beta$, IL-6, IL-17, IL-12, IL-2, anti-inflammatory cytokine IL-10 and hemopoietic growth factors M-CSF, GM-CSF in supernatants obtained from cultures of RAW264.7 macrophages after the 24 or $48 \mathrm{~h}$ treatment (Figure 3). Stimulation of RAW 264.7 cells with glycoconjugate GM-1 for $24 \mathrm{~h}$ resulted in a significant increase of TNF $\alpha$ (1.8-fold), IL-17 (1.8-fold), and GM-CSF (1.4-fold) production using a concentration of $10 \mu \mathrm{g} / \mathrm{mL}$. Higher GM-1 conjugate concentration $(100 \mu \mathrm{g} / \mathrm{mL})$ induced a more intense statistically significant increase of TNF $\alpha$ (2.9-fold), IL-17 (3.1-fold), and GM-CSF (1.8-fold) production and in addition increase of IL-6 (2.5-fold), IL-12 (1.9-fold), and IL-2 (2.1-fold), production during the 24-h treatment. Stimulation of RAW 264.7 cells with glycoconjugate GM-1 for $48 \mathrm{~h}$ increased the M-CSF (1.9-fold) and IL-12 (1.9-fold) production by using concentration $10 \mu \mathrm{g} / \mathrm{mL}$. The higher GM-1 concentration $(100 \mu \mathrm{g} / \mathrm{mL})$ during 48-h stimulation induced a statistically significantly higher production, compared to the control, of mainly all analyzed cytokines except for pro-inflammatory cytokine TNF $\alpha$ (0.7-fold lower than control).

After the 24-h treatment at higher GM-1 concentration $(100 \mu \mathrm{g} / \mathrm{mL})$ the production of pro-inflammatory cytokines TNF $\alpha$, IL-6, IL-17, IL-12, IL-2, and hemopoietic growth factor GM-CSF were more efficiently induced compared to the lower GM-1 concentration $(10 \mu \mathrm{g} / \mathrm{mL})$. The $48-\mathrm{h}$ simulation period of RAW 264.7 cells determined the $100 \mu \mathrm{g} / \mathrm{mL}$ concentration of glycoconjugate GM-1 as a preferable inducer of IL-6, IL-17, IL-12, IL-2, and both hemopoietic growth factors (M-CSF and GM-CSF) production (Figure 3). The stimulation of RAW 264.7 cells with glycoconjugate GM-1 did not significantly influence the IL- $1 \beta$ and IL-10 production (Figure 3 ).

The 24-h stimulation period of RAW 264.7 cells with $10 \mu \mathrm{g} / \mathrm{mL}$ concentration of glycoconjugate GM-2, likewise GM-1 conjugate, significantly increased the production of pro-inflammatory cytokines TNF $\alpha$ (2.8-fold), and IL-17 (1.6-fold), but without effect on GM-CSF production. The higher GM-2 concentration $(100 \mu \mathrm{g} / \mathrm{mL})$ possess similarly as GM-1 higher ability of cytokines induction and evoked an increase in the production of mainly all cytokines, with the highest effect on TNF $\alpha$ (6.3-fold), IL-6 (17.4-fold), IL-17 (9.3-fold), IL-12 (12.5-fold), and IL-2 (3.6-fold) production. After the longer 48-h stimulation period, the $10 \mu \mathrm{g} / \mathrm{mL}$ concentration of glycoconjugate GM-2 increased the production of IL-6 (1.4-fold), M-CSF (1.4-fold), IL-17 (1.3-fold), and IL-12 (1.9-fold). Contrary to $(1 \rightarrow 6)$-linked glycoconjugate GM-1, the 48-h stimulation of RAW 264.7 cells with $(1 \rightarrow 3)$-linked isomer GM-2 at $100 \mu \mathrm{g} / \mathrm{mL}$ concentration did not significantly increase the production of GM-CSF and IL-2, and induced a statistically significant increase of IL-6 (7.7-fold), M-CSF (1.4-fold), IL-17 (1.8-fold), and IL-12 (13.9-fold) production. Similarly as with glycoconjugate GM-1, the stimulation of RAW 264.7 cells with GM-2 did not significantly influence the IL-1 $\beta$ and IL-10 production (Figure 3).

At higher concentration of $100 \mu \mathrm{g} / \mathrm{mL}$, glycoconjugate GM2 more efficiently induced an increase in analyzed cytokines for both monitored time periods (24 and $48 \mathrm{~h}$ ). The $10 \mu \mathrm{g} / \mathrm{mL}$ concentration of glycoconjugate GM-2 evoked a time-dependent increase in cytokines production, favoring 48-h stimulation period. The $100 \mu \mathrm{g} / \mathrm{mL}$ concentration of GM-2 more efficiently induced the production of cytokines during the 24-h stimulation time period (Figure 3).

Cell culture media following 24- and 48-h RAW 264.7 exposure with glycoconjugates GM-1 and GM-2 were assayed for free radicals release. The resulting values were compared with control (untreated cells) and with ConA or PHA treated cells (Figure 4).

Evidently, free radicals had been triggered only with a $100 \mu \mathrm{g} / \mathrm{mL}$ concentration of glycoconjugate GM-1 following 24-h exposure; media release has been higher by $7 \%$ compared to untreated control. The concentration-dependent increasing trend has been observed for GM-1 conjugate: $100 \mu \mathrm{g} / \mathrm{mL}$ concentration induces 10 and $4 \%$ increases in free radicals media levels following 24 and $48 \mathrm{~h}$ over the $10 \mu \mathrm{g} / \mathrm{mL}$ concentration induction, although the induced free radicals production did not significantly exceed the basal free radicals production of untreated RAW 264.7 cells. This tendency was not manifested with glycoconjugate GM-2. The overall inductive free radicals release caused by glycoconjugates GM-1 and GM-2 was apparently lower in comparison with ConA induction, except for 24-h treatment with glycoconjugate GM-1 $(100 \mu \mathrm{g} / \mathrm{mL})$ resulting in $4 \%$ increase over the ConA induced level, and significantly lower than PHA induction of free radicals release (Figure 4).

\section{GM-1 and GM-2 Glycoconjugates Effect on the Phagocytic Activity of RAW264.7 Cells}

The influence of glycoconjugates GM-1 and GM-2 on RAW 264.7 functionality has been evaluated on the basis of phagocytic capability. The phagocytic activity of exposed RAW264.7 cells and ingestion of $C$. albicans-FITC complex have been determined following 24 - and 48-h exposure, respectively, with 10 and $100 \mu \mathrm{g} / \mathrm{mL}$ of both pentasaccharides GM-1 and GM-2. 
GM-1

Control $\square 10 \mu g \square 100 \mu g \square$ Con A $\square$ PHA
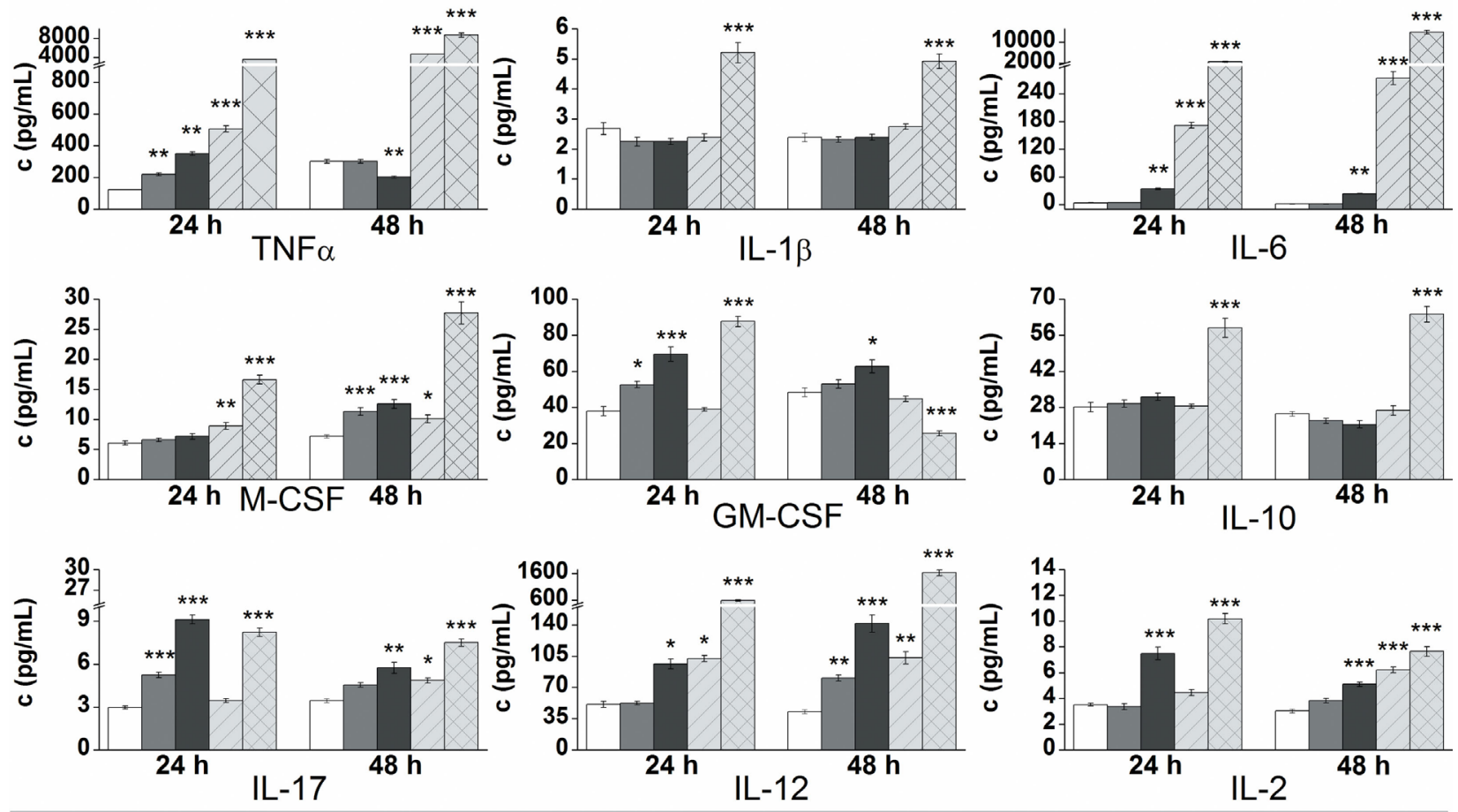

GM-2
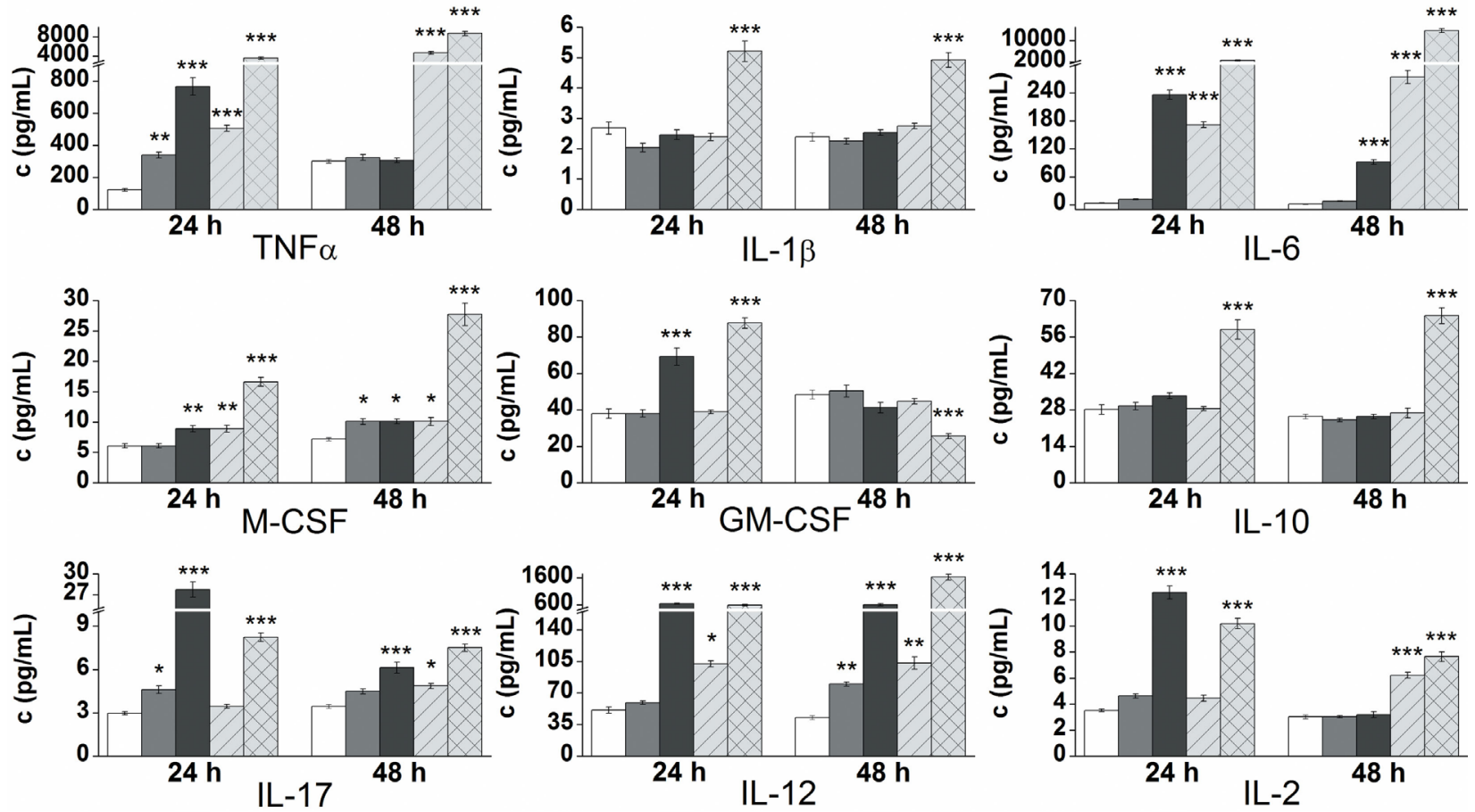

FIGURE 3 | Effect of glycoconjugates GM-1 and GM-2 on RAW 264.7 macrophages cytokines production. Concentrations of cytokines in media after 24- or 48-h stimulation of RAW 264.7 macrophages in response to stimulation with 10 or $100 \mu \mathrm{g} / \mathrm{mL}$ concentration of glycoconjugates $\mathbf{G M - 1}$ or $\mathbf{G M - 2}$, to positive controls concanavalin A (Con A, $10 \mu \mathrm{g} / \mathrm{mL}$ ) and phytohemagglutinin (PHA, $10 \mu \mathrm{g} / \mathrm{mL}$ ). Negative control represents untreated RAW 264.7 cells (Control). All data are presented as Mean \pm SD. Tests were carried out in triplicate. The statistical significance of differences between stimulated cells and untreated cells using one-way ANOVA and post hoc Bonferroni's tests is expressed: ${ }^{* * *}-P<0.001,{ }^{* *}-0.001<P<0.01,{ }^{*}-0.01<P<0.05$. 
To discriminate internalized FITC-labeled Candida cells from those attached to the cell membrane trypan blue, the quenching method has been applied as the cells attached to the cell membrane can be quenched (Table 1).

The immunocytometric assay of RAW 264.7 cells exposed to glycoconjugates GM-1 and GM-2 revealed the influence on effective phagocytosis of C. albicans-FITC complex. Evidently, both oligosaccharides exerted rather different effects especially on the process of cellular ingestion and internalization (Table 1). The amount of internalized C. albicans-FITC cells following the 48-h exposure of glycoconjugates GM-1 at a concentration of $10 \mu \mathrm{g} / \mathrm{mL}$ resulted in a 16.1 -fold decrease $(P<0.001)$ and following exposure with a concentration of $100 \mu \mathrm{g} / \mathrm{mL}$ the similar 17.2 -fold decrease $(P<0.001)$ vs. untreated control has been determined. Compared to the results reached with glycoconjugate GM-2, the 17.4-fold decrease (at $10 \mu \mathrm{g} / \mathrm{mL}$ ) and 16.6-fold (at $100 \mu \mathrm{g} / \mathrm{mL}$ ) decrease have been detected after 48 -h exposure. RAW 264.7 cells exposure to glycoconjugate GM-2 did not regulate the ability of macrophage cells to phagocyte the

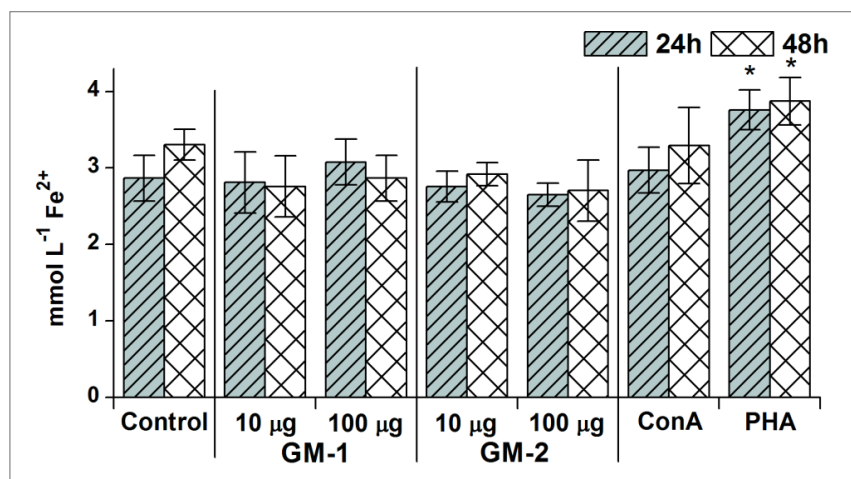

FIGURE 4 | Concentration- and time-dependent pattern of free radicals' release. The release after 24 or 48 h stimulation of RAW264.7 macrophages in response to stimulation with 10 or $100 \mu \mathrm{g} / \mathrm{mL}$ concentration of glycoconjugates $\mathbf{G M - 1}$ or $\mathbf{G M - 2}$ and to concanavalin $\mathrm{A}$ (Con A, $10 \mu \mathrm{g} / \mathrm{mL}$ ) and phytohemagglutinin (PHA, $10 \mu \mathrm{g} / \mathrm{mL}$ ) as a positive controls; control represents untreated cells (Control). All data are presented as mean $\pm \mathrm{SD}$. Tests were carried out in triplicate. The statistical significance of differences between stimulated cells and untreated cells using one-way ANOVA and post hoc Bonferroni's tests is expressed: * $-0.01<P<0.05$.
C. albicans-FITC complex, and correlation analysis vs. control reveled $r=0.938(10 \mu \mathrm{g} / \mathrm{mL}$ concentration $)$ and $r=0.981$ $(100 \mu \mathrm{g} / \mathrm{mL})$.

\section{The Influence of Conjugates GM-1 and GM-2 on RAW264.7 Macrophages Cell Surface Antigens F4/80 and CD11b Expression}

To establish the influence of conjugates GM-1 and GM-2 24- and 48-h exposure on RAW264.7 macrophage cell-line, the macrophages major cell surface antigens $\mathrm{F} 4 / 80$ and $\mathrm{CD} 11 \mathrm{~b}$ (Mac-1 $\alpha$; integrin $\alpha \mathrm{M}$ chain part of the CD11b/CD18 heterodimer) expression has been followed (Figure 5). The treatment of RAW264.7 macrophage cells with glycoconjugates GM-1 or GM-2 at 10 or $100 \mu \mathrm{g} / \mathrm{mL}$ concentrations resulted in almost unchanged (24-h treatment) or a statistically insignificantly decreased (48-h treatment) CD11b expression, compared to non-treated control cells, except for significant decrease after 48-h treatment with glycoconjugate $\mathbf{G M - 2}$ at $10 \mu \mathrm{g} / \mathrm{mL}$ concentration (33\% decrease vs. control, $P<0.05)$. Comparing the individual conjugates in the context of the behavior of exposed RAW264.7 cells an increasing tendency of both surface antigens has been observed in the concentration- and time-dependent manner following the treatment with compounds GM-1 or GM-2 (Figure 5). The overall increase vs. control, i.e., untreated cells, has not been observed.

The kinetics of membrane protein $\mathrm{F} 4 / 80$ expression exerts the same trend; the expression of $\mathrm{F} 4 / 80$ is time- and concentrationdependent (Figure 5). The 24- and 48-h stimulation period of RAW 264.7 with $100 \mu \mathrm{g} / \mathrm{mL}$ concentration of glycoconjugate GM-2 significantly increased the F4/80 expression over the expression triggered with $10 \mu \mathrm{g} / \mathrm{mL}$ (1.52-fold increase, $P<0.05)$. The decreasing trend of kinetics of $\mathrm{F} 4 / 80$ and $\mathrm{CD} 11 \mathrm{~b}$ following exposure with both structures, compared to control, i.e., untreated cells, has been more evident for isomer GM-1 vs. control (2.96-fold for $10 \mu \mathrm{g} / \mathrm{mL}$ and $24 \mathrm{~h}, 2.2$-fold for $100 \mu \mathrm{g} / \mathrm{mL}$ and $24 \mathrm{~h}$ vs. 1.39-fold and 1.17-fold for GM-2 conjugate at the same time and concentration conditions).

The correlation between the time- and concentration-dependent CD11b and F4/80 expression on RAW264.7 macrophage cells following the exposure to $(1 \rightarrow 6)$-linked isomer GM-1 was $r=0.96$

TABLE 1 | RAW264.7 macrophage phagocytosis of C. albicans-FITC (\%) following 24- and 48-h cell treatment with glycoconjugates GM-1 and GM-2 analyzed by flow cytometry.

\begin{tabular}{|c|c|c|c|c|c|c|c|}
\hline \multirow[t]{2}{*}{ Sample } & \multirow[t]{2}{*}{ Dose, $\mu \mathrm{g} / \mathrm{mL}$} & \multicolumn{2}{|c|}{$\begin{array}{l}\text { Cell bound and internalized } \\
\text { C. albicans-FITC }\end{array}$} & \multicolumn{2}{|c|}{ Internalized C. albicans-FITC } & \multicolumn{2}{|c|}{$\begin{array}{l}\text { Membrane attached } \\
\text { C. albicans-FITC }\end{array}$} \\
\hline & & $24 \mathrm{~h}$ & $48 \mathrm{~h}$ & $24 \mathrm{~h}$ & $48 \mathrm{~h}$ & $24 \mathrm{~h}$ & $48 \mathrm{~h}$ \\
\hline \multirow[t]{2}{*}{ GM-1 } & 10 & $24.4 \pm 2.3$ & $27.4 \pm 2.1^{\star *}$ & $4.8 \pm 1.2^{\star \star}$ & $1.6 \pm 0.2^{\star \star \star}$ & $19.6 \pm 0.5^{\star}$ & $25.8 \pm 1.6$ \\
\hline & 100 & $21.7 \pm 1.9$ & $28.9 \pm 1.7^{\star \star}$ & $2.1 \pm 0.9^{\star \star}$ & $1.5 \pm 0.3^{\star \star \star}$ & $18.9 \pm 0.9^{*}$ & $27.4 \pm 0.9$ \\
\hline GM-2 & 10 & $51.3 \pm 3.4^{* *}$ & $63 \pm 2.9$ & $7.7 \pm 0.8$ & $27.8 \pm 2.5$ & $43.6 \pm 2.2^{\star \star}$ & $35.2 \pm 1.7$ \\
\hline
\end{tabular}

Control represents untreated cells (Control). The amount of membrane attached C. albicans-FITC is expressed as a difference between the population of cell membrane attached and cell internalized C. albicans-FITC and Trypan blue unquenched population, i.e., internalized cells. All data are presented as Mean \pm SD. Tests were carried out in triplicate. The statistical significance of differences between untreated cells and stimulated cells using one-way ANOVA and post hoc Bonferroni's tests is expressed as: ${ }^{* *}-P<0.001$, ${ }^{* *}-0.001<P<0.01,{ }^{*}-0.01<P<0.05$. 
A
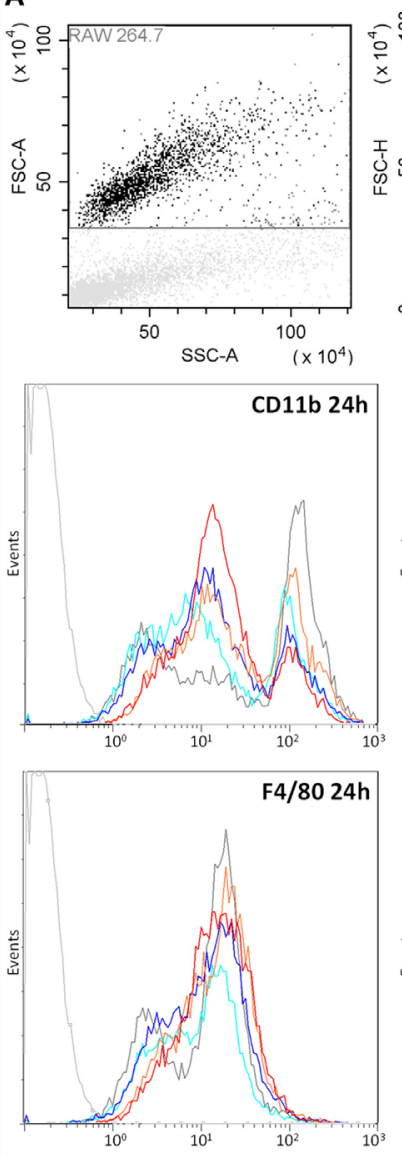
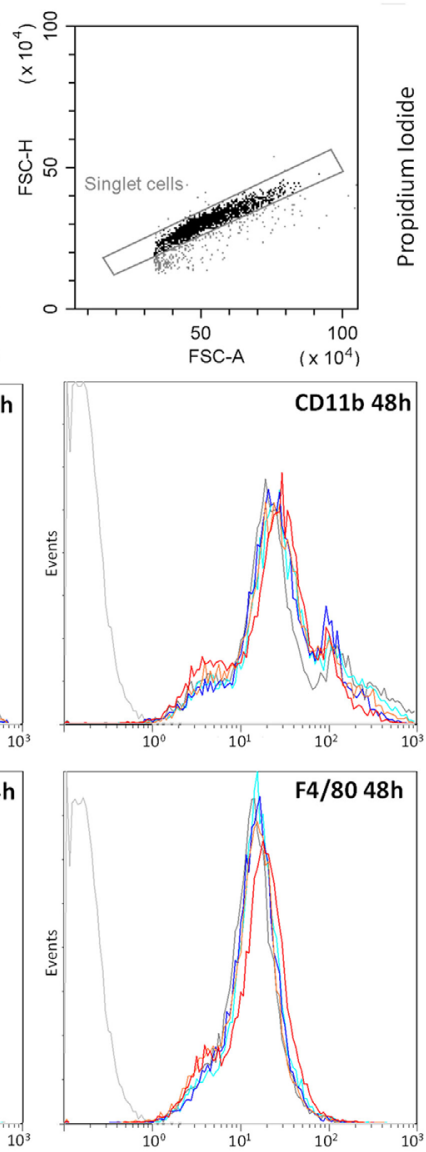
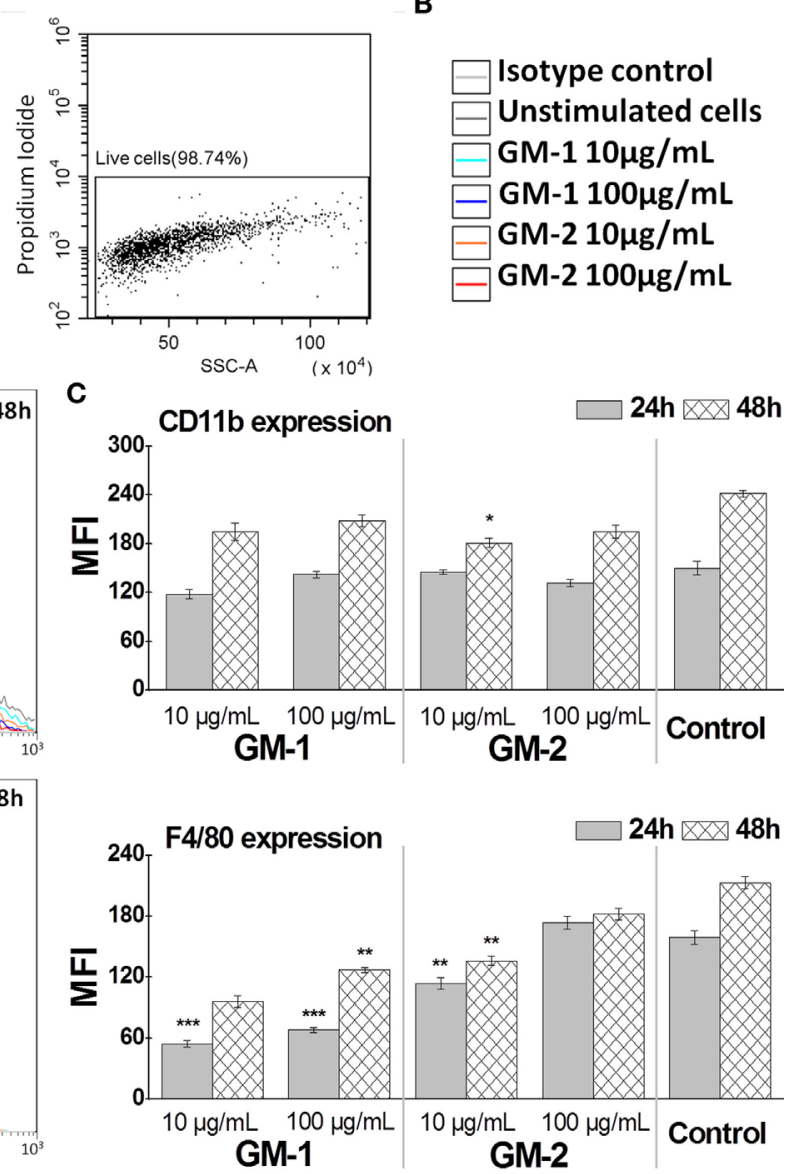

FIGURE 5 | Immunocytometric measurement of RAW264.7 macrophage cell-line expression of major cell surface antigens F4/80 and CD11b following of the treatment by glycoconjugates GM-1 or GM-2 at 10 or $100 \mu \mathrm{g} / \mathrm{mL}$ concentrations. Gates were set to exclude the cellular debris using forward scatter vs. side scatter dot plot discrimination, doublets and dead cells (A). The settings were optimized using proper isotype control. Fluorescence histograms (B) of 10,000 cells were generated and analyzed (green fluorescence, 525-nm band-pass filter). The data (C) are expressed as a mean of fluorescence intensity. The statistical significance of differences between untreated cells (Control) and stimulated cells using one-way ANOVA and post hoc Bonferroni's tests is expressed as follows: ${ }^{\star \star \star}-P<0.001$, ${ }^{\star *}-0.001<P<0.01,{ }^{*}-0.01<P<0.05$.

and while following the exposure to $(1 \rightarrow 3)$-linked GM-2 it was $r=0.46$.

\section{Sera Levels of Anti-GM-1 and -GM-2 $\lg G$, IgA, and IgM Isotypes}

Sera levels of anti-GM-1 and anti-GM-2 antibodies were assayed in Candida vulvovaginitis patients and healthy controls (blood donors) (Figure 6). Evidently, the class distribution of anti-GM-1 and anti-GM-2 antibodies has revealed IgM as the highest abundant isotype, followed by IgA and IgG. Statistically, the most significant have been the sera levels of IgM antiGM-1 $(P<0.01)$ and IgM anti-GM-2 $(P<0.01)$. The correlation between these two anti-pentasacchride specific IgMs is 0.99 . The sera values of antigen specific IgM anti-GM-1 were 3.92-fold increased vs. blood donors' values; and for specific IgM anti-GM-2 the 5.33-fold increase has been observed. Both pentasaccharide IgM isotypic antibodies were significantly lower in comparison with anti-C. albicans mannan antibodies, i.e., for IgM anti-GM-2 (declined by $31.9 \%, P<0.001, r=0.96$ ) and for IgM anti-GM-1 the reduction was $35.22 \%(P<0.01$, $r=0.95)$.

The next most profound reactive isotype in the vulvovaginitis group has been IgA anti-GM-1 demonstrated a 2.02-fold increase compared to healthy controls $(P<0.05)$. The 1.7 -fold increase in specific IgA anti-GM-2 over the healthy blood donors values has been statistically insignificant. The comparison with Candida mannan IgA response revealed a high correlation with anti-GM-1 $(r=0.97)$ and a lower one for anti-GM-2 $(r=0.81)$. Both pentasaccharides revealed similar IgA response compared to $C$. albicans mannan (Figure 6). The IgG antigen-specific response has been 1.81-fold increased with pentasaccharide GM-1 over blood donors values and almost comparable with anti-mannan $\operatorname{IgG}(r=0.98)$. The IgG anti-GM-2 level was 1.09 times higher in the vulvovaginitis group than that in the control group. The vulvovaginitis group exerted a 2.52-fold decrease in anti-GM-2 pentasaccharide IgG compared to anti-mannan IgG $(r=0.76)$. 


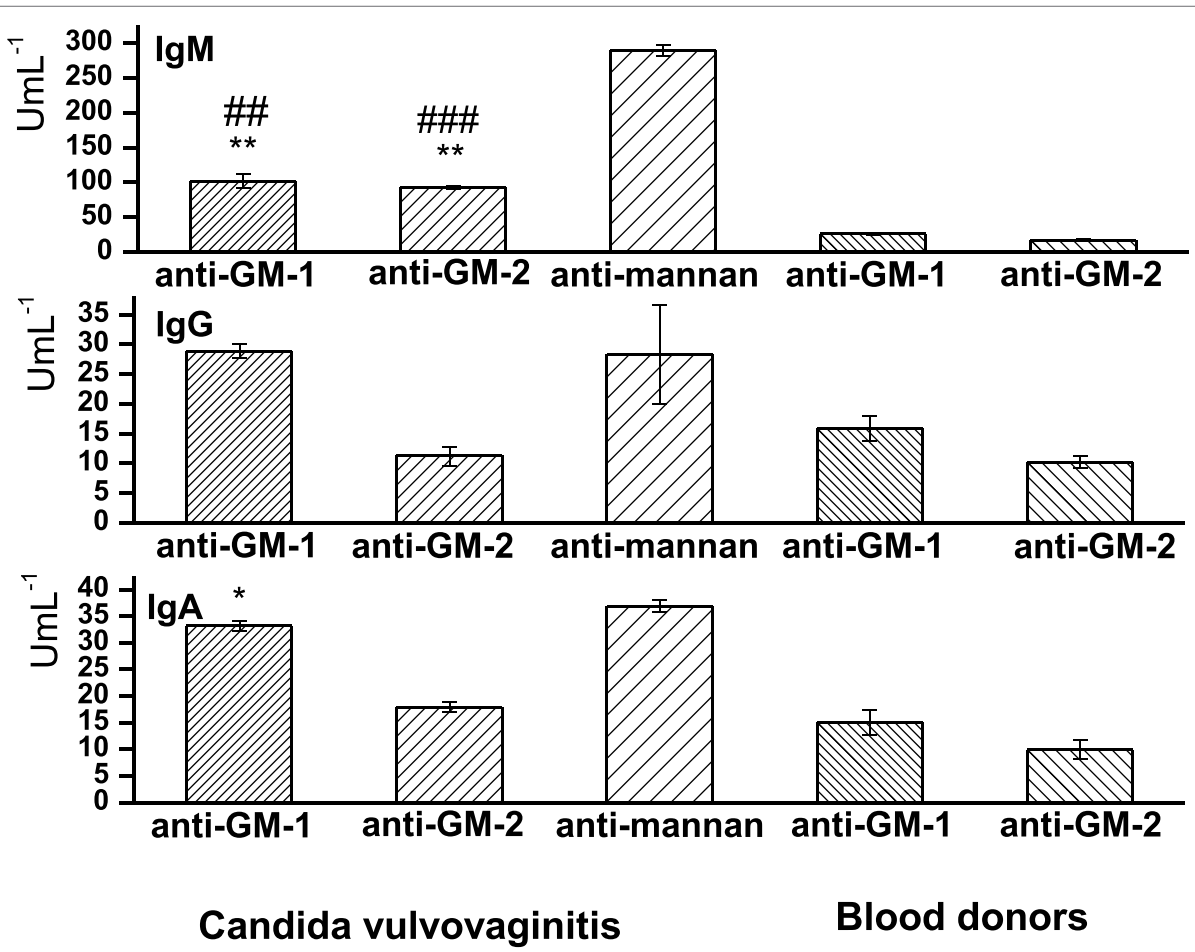

FIGURE 6 | Distribution of sera levels of anti-GM-1, anti-GM-2, and anti-mannan isotype class antibodies in vulvovaginitis patients and healthy controls (blood donors). Data are presented as mean \pm SD. Analyses were carried out in triplicate. The statistical significance of differences between controls (blood donors) and vulvovaginitis patients using one-way ANOVA and post hoc Bonferroni's tests is expressed as: ${ }^{*}-0.001<P<0.01$, ${ }^{*}-0.01<P<0.05$. The statistical significance of differences between anti-mannan Abs and anti-GM-1 and anti-GM-2 Abs using one-way ANOVA and post hoc Bonferroni's tests is expressed as follows:

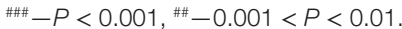

\section{DISCUSSION}

The mold A. fumigatus is characterized by three morphotypes: (i) resting conidia, (ii) swollen conidia, and (iii) hyphae. The cell-walls of the mycelium and conidium are different especially at the level of the surface layer, which plays a significant role in the specific recognition of invading A. fumigatus by phagocytic cells of the immune system (24). The recognition of A. fumigatus conidia and hyphae is mediated by pattern recognition receptors (PRRs) either soluble and/or cell-bound receptors. The cell wall and its constituents symbolize the remarkable host-invader communication interface. Conidial germination starts with hydrophobic layer degradation and exposure of inner cell wall components, mainly polysaccharides such as chitin, $\beta$-glucan, mannan, and galactomannan. These represent pathogen-associated molecular patterns (PAMPs) recognized by PRRs $(35,36)$. Rizetto et al. (37) showed that the immune response induced by Aspergillus spp. may be dependent on variations of the fungus strain that could present diverse virulence factors and therefore increased or reduced infectivity. Generally, toll-like receptors and C-type lectin receptors as TLR2, TL4, and TLR9, Dectin-1, Dectin-2, DC-SIGN, mannose receptor, etc. on phagocytes directly recognize surface ligands on A. fumigatus and participate in pro-inflammatory and anti-inflammatory signaling responses resulting in cytokine and reactive oxygen species (ROS) release, thus supporting the antifungal activity (38-41). Of note, several polymorphisms of human TLRs, e.g., TLR1, TLR2, TLR4, TLR6, or TLR9, have been associated with increased risk of invassive aspergillosis in susceptible hosts (42-44).

Various interleukins and growth factors are engaged in host inter-reactivity with A. fumigatus. Bozza et al. (22) revealed that different preparations of $A$. fumigatus antigens induced the expansion of various CD4 T-cell subsets with secreted antigens promoting the differentiation of Th2 cells, membrane components Th1 cells, and glycolipids Th17 cells. In murine models of aspergillosis, $\alpha$ - $(1 \rightarrow 3)$-glucan and $\beta$-( $(1 \rightarrow 3)$-glucan chains induce a protective response through the activation of Th1 and Th17 or Treg responses, whereas galactomannan favors the disease through the activation of the Th2/Th17 response (22).

In invasive aspergillosis, Th1-cell responses are associated with the resistance and onset of protective immunity, whereas Th2 responses are associated with progressive disease, more tissue damage, and poor survival. Th1-produced cytokines, including interferon- $\gamma$, interleukins IL-6, IL-12, TNF- $\alpha$, and IL-1 activate neutrophils and pulmonary macrophages, the key effector cells in invasive aspergillosis, whereas Th2 cytokines, particularly IL- 4 and IL-10, are associated with reduced IL-12 and TNF- $\alpha$ and worse outcome (45). Interestingly, the profile of the cytokine pattern depends on various aspects, such as the route of infection, immunological status of the host, type of Aspergillus antigens, etc. $(2,46,47)$. 
RAW 264.7 exposure to glycoconjugates GM-1 and GM-2 resulted in the accelerated cell-release of Th1 pro-inflammatory cytokines (Figure 3), TNF- $\alpha$, IL-6, IL-12, IL-2, and hemopoietic growth factors GM-CSF and M-CSF associated with antiA. fumigatus responses, this cytokine pattern is consistent with the results of Roilides et al. (48). Moreover, the G-CSF, GM-CSF, and M-CSF are cytokines with promising therapeutic efficacy and play critical roles in the host defense response during infection $(49,50)$. In vitro M-CSF has been shown to augment the antifungal activity of monocytes/macrophages against both conidia and hyphae of $A$. fumigatus, partly via enhancement of oxidation-dependent mechanisms (49).

Next, in a response to isomers GM-1 and GM-2 stimuli, the enhancement of media-release of IL-17 has been revealed. IL-17, signature cytokine of Th17 cells, is engaged in antimicrobial protection and induction of inflammation (51). Chai et al. has pointed out the role of this unique cytokine in Th17 antiA. fumigatus immune responses (46). The Th1/Th17 polarized increased reactivity of the relevant signature cytokines TNF-a, IL-12, IL-17, IL-6, and IL-2 has been evidently structuredependent, more apparent with $(1 \rightarrow 3)$-linked GM-2, especially with $100 \mu \mathrm{g} / \mathrm{mL}$ concentration.

Resistance to A. fumigatus infection is associated with high levels of Th1 cytokines including IL-2, IL-12, and TNF- $\alpha$ (4). The statistically significant high media levels $(P<0.001)$ of these cytokines have been detected following the exposure with glycoconjugates GM-1 and GM-2 (Figure 3). On the contrary, disease progression is associated with Th2 cytokines IL-4 and IL-10 (4). Evidently, both galactomannosides GM-1 and GM-2 did not induce the significant IL-10 release over basal levels of untreated RAW2 64.7 cells (1.14-fold increase with $100 \mu \mathrm{g} / \mathrm{mL}$ of $\mathbf{G M}-1$ and 1.19-fold increase with $100 \mu \mathrm{g} / \mathrm{mL}$ of GM-2) (Figure 3).

Concerning concentration- and time-dependent cytokines' release following cell exposure to glycoconjugate GM-1, the statistically significant tight correlations have been revealed between TNF- $\alpha$ and IL-1 $\beta(r=0.96562, P=0.03438)$; IL-6 $(r=0.99394, P=0.00606)$; M-CSF $(r=0.99869, P=0.00131)$, IL-12 $(r=0.99885, P=0.00115) ;$ IL-2 $(r=0.92829$, $P=0.04171)$; IL-17 $(r=0.94871, P=0.04129)$; and IL-10 $(r=-0.91585, P=0.0325)$. Correlation analysis confirmed the similar trends of kinetics of these cytokines release also with isomer GM-2. The cell exposure to this compound $(10 \mu \mathrm{g} / \mathrm{mL})$ resulted in a tight correlation exerted by TNF- $\alpha$ and IL-1 $\beta$ $(r=0.87965, P=0.012035)$; IL-6 $(r=0.99453, P=0.00547)$; M-CSF $(r=0.99938, P=0.000623)$; GM-CSF $(r=0.99291$, $P=0.00709)$; IL-12 $(r=0.99968, P=0.000315)$; IL-2 $(r=0.9579$, $P=0.04205)$, IL-17 $(r=0.97497, P=0.02503)$; and IL-10 $(r=-0.90181, P=0.0411)$.

Obviously, the Th1/Th17 prospectively antifungal protective immunobiological efficiency could be assumed. Conjugates GM-1 and GM-2 induced IL-10 tight negative correlation with TNF- $\alpha$, associated with anti-inflammatory signaling are of interest. According to the observed time-dependent downregulation of several cytokines (from 24 to $48 \mathrm{~h}$ treatment), we can hypothesized engagement of relevant cytokine receptors and their interactions with media-produced cytokines subsequently resulting into the binding and uptake of released cytokine and regulatory feedback loop between cytokines and immune cells.

Thus, both synthetically prepared compounds GM-1 and GM-2 partially mimicking the Aspergillus galactomannan represented the appropriate model structures for in vivo and in vitro immunobiological studies. Their immunocompatibility has been confirmed based on the tests on functionality of RAW 264.7 macrophages treated with GM-1 and GM-2, i.e., the trend of cell-line expression of major cell surface antigens F4/80 and CD11b following cell-exposure (Figure 5). Both markers represent pan macrophage antigens involved in cell adhesion and presumably in cell-cell interactions (F4/80) and, chemotaxis, phagocytosis, and apoptosis (CD11b) (Figure 5).

The induced changes of F4/80 expression demonstrated the association with concentration of glycoconjugates and exposition time as detected by cell-proliferation and phagocytosis. The free radical release did not exert this tendency (Figure 4).

The physiological concentration of ROS is essential to prevent immunometabolic disturbances. Oxidative stress induced by free radicals has been associated with the development of various diseases (52).

Obviously, phagocytosis plays the central role in antiAspergillus immunity. Innate effector phagocyting cells comprise alveolar macrophages, dendritic cells, neutrophils, and monocytes engaged in processes of hyphae and conidia engulfment, internalization, and killing via oxidative or non-oxidative mechanisms. In vitro studies documented the delay of conidial killing by alveolar macrophages after phagocytosis corresponding to the time when conidia become swollen (44). Interestingly, conidial phagocytosis involved DC-SIGN and complement recepor 3 and resulted in a protective Th1 response, while hyphal phagocytosis via Fc receptor and complement receptor 3 generates an unfavorable Th2 response (44). The experiments on RAW 264.7 phagocytosis and Candida internalization triggered by glycoconjugates GM-1 and GM-2 revealed a more efficient cell attachment and internalization with $(1 \rightarrow 3)$-linked GM-2 over $(1 \rightarrow 6)$-linked GM-1 (Table 1). Presumably, the structural epitopes of this formula resembled those of natural galactomannan more tightly compared to glycoconjugate GM1. Evidently, both conjugates are able to initiate the process of phagocytosis, accompanied especially by the release of TNF- $\alpha$, IL-6, IL-12, IL-2, Il-17 cytokines, and hemopoietic growth factors GM-CSF and M-CSF contributing to the regulation of inflammation (Figure 3). The significant increase of cell bound and internalized C. albicans cells by RAW 264.7 macrophages has been detected following $24 \mathrm{~h}$ cell pre-exposition with GM-2 at $10 \mu \mathrm{g} / \mathrm{mL}(P<0.01)$ and $100 \mu \mathrm{g} / \mathrm{mL}(P<0.05)$.

Although the exposition of RAW 264.7 to GM-1 upregulated the secretion of these cytokines and growth factors (Figure 3) to lesser degree than GM-2, the sequential process of phagocytosis has been inhibited (Table 1). Yet, we are not able fully to explain the decrease in phagocytosis despite the increase in Th1 type of cytokines. According to the known antigenic cross-reactivity between Aspergillus spp. and Candida spp. (53), one can suppose the interactions between C. albicans cellular PAMPs (e.g., mannan), GM-1 and relevant RAW 264.7 PRRs. Evidently, GM-1 comprised more cross-reactive 
epitopes reflecting the structure of candidal ones. This item needs further investigation.

Thus, the engagement of isomer $(1 \rightarrow 3)$-linked GM-2 in processes of recognition (recognition receptors DC-SIGN, Dectin-1, or TLRs) and subsequent attachment, engulfment and internalization is obviously over $(1 \rightarrow 6)$-linked isomer GM-1. The DC-SIGN receptor binds dormant Aspergillus conidia in a galactomannan-dependent manner leading to the internalization of spores (54).

The commercial diagnostics of aspergillosis is based on EB-A2 monoclonal antibody reacting with the specific epitope of galactomannan. It is an IgM antibody with an avidity constant of $2 \times 10^{9}-5 \times 10^{9} \mathrm{M}$ binding to an epitope located on the $\beta-(1 \rightarrow 5)$ galactofuranosyl-containing side chain of the galactomannan molecule. The epitope recognized by the EB-A2 $\mathrm{MAb}$ is a common oligosaccharide moiety of a wide range of intracellular and extracellular glycoproteins of Aspergillus species EB-A2, and similar epitope seems to be present in other fungi $(55,56)$. Galactomannan is not unique to Aspergillus sp., apart from Aspergillus sp. galactomannan is found in different amounts also in Penicillium, Fusarium, Alternaria, and Histoplasma $(57,58)$. Moreover, Swanink et al. (53) suggested the reactivity of Candida sp. in galactomannnan assay due to cross-reacting antigens. In Aspergillus, histochemistry false positive staining of Candida was observed with both polyclonal and monoclonal Aspergillus antibodies (59). The serapositivity of anti-GM-1 and -GM-2 isotypic antibodies in Candidacolpitis cohort demonstrated the cross-reactivity of Asperillus related structures GM-1 and GM-2 (Figure 6). Evidently, these structures comprised the main cross-reactive epitopes.

For comparison, sera from vulvovaginitis patients have been subjected to seradiagnostics based on glycoconjugates GM-1 and GM-2, in parallel with Candida mannan assay. The pattern of antigenspecific IgM > IgA > IgG immune responses reactive with structures GM-1 and GM-2 (Figure 6) reflected the previously observed kinetics of anti-C. albicans mannan and anti-C. albicans glucan antibodies in atopic patients suffering from vulvovaginitis (34), thus suggesting the immunobiological importance of such fungal oligoglycosidic structures. Our recent findings demonstrate the IgM as dominant isotype also in serological studies of Candida vulvovaginitis patients using different synthetically prepared glycosides (60). Generally, specific anti-glycoside IgM is elevated in active fungal infection along with IgA, while elevated antigen-specific IgG are characteristic for reccurent attacks (61). Nowadays, the specific role of natural IgM antibodies has been stressed $(62,63)$.

The Aspergillus gynecological infections are rare, according to MEDIREX Inc., HPL Mycology Labs., Slovakia, Aspergillus sp. represent 1/5,500 of all positive mycological isolates from uterus and cervix. Gupta et al. (64) reported simultaneous infection with Aspergillus sp. and cervical squamous cell carcinoma in the female genital tract attributed to the opportunistic nature of infection in the immunocompromised state due to the underlying malignancy. Genitourinary aspergillosis is rare in non-immunocompromised patients, only few reports have been documented (65-67).

\section{CONCLUSION}

The ability of synthetically prepared isomeric galactomannoside derivatives GM-1 and GM-2 related to Aspergillus galactomannan antigen to interact with murine macrophages RAW 264.7 was studied. Significant immunomodulative effectivity of glycoconjugates GM-1 and GM-2 has been established via proliferation/cytotoxicity assay, phagocytosis and inductive interleukins and growth factors release. The protective Th1 and Th17 polarization has been revealed, especially with $(1 \rightarrow 3)$-linked GM-2, which is more efficient trigger of the internalization and of Candida engulfment by RAW 264.7 cells.

The sera-crossreactivity with glycoconjugates GM-1 and GM-2 observed in vulvovaginitis patients revealed the clinical relevance of studied pentasccharide chains especially one with $\beta$ Galf- $(1 \rightarrow 6)-\alpha$ Man fragment present in the pentasaccharide GM-1.

In conclusion, it can be stated that synthetically prepared glycoconjugates GM-1 and GM-2 partially mimicking the structure of Aspergillus galactomannan represent the suitable in vitro and prospectively in vivo models for further immunobiological and immunotoxicological studies, potential antigens for in vitro diagnostics of aspergillosis and antifungal therapy monitoring.

\section{ETHICS STATEMENT}

The research protocol and the study have been approved by the Local Ethical Committee of the Oncology Institute of St. Elisabeth, Bratislava, Slovakia. Written informed consent to participate in the research study and for blood collection and subsequent laboratory examinations, in accordance with the principles in the Helsinki Declaration, was obtained from each patient prior to study enrollment. Patient's age, disease process, drug history, family history, and clinical signs and symptoms were documented at the first visit.

\section{AUTHOR CONTRIBUTIONS}

EP-executed the experimental design and performance of immunobiological studies, performed the human serodiagnostics, analyzed and interpreted the data. LP-performed immunobiological experiments and graphic data evaluation. $\mathrm{MH}$-identified patient cohort, determined patient feasibility, and managed patient recruitment for the trial. VK and DA-performed the chemical syntheses of the oligosaccharide derivatives and analyzed the results. NN-planned the synthetic study, analyzed the results of synthetic part, and compared the data with contemporary literature.

\section{FUNDING}

This work was supported by the Scientific Grant Agency of the Slovak Republic VEGA (project 2/0098/17) and by the Slovak Research and Development Agency under the contract No. APVV-15-0161. The synthetic part of the work was supported by the RSF (grant 14-23-00199 to NN). 


\section{REFERENCES}

1. Lehrnbecher T, Groll AH. Invasive fungal infections in the pediatric population. Expert Rev Anti Infect Ther (2011) 9(3):275-8. doi:10.1586/eri.11.1

2. Romani L. Cell mediated immunity to fungi: a reassessment. Med Mycol (2008) 46(6):515-29. doi:10.1080/13693780801971450

3. Weaver CT, Hatton RD, Mangan PR, Harrington LE. IL-17 family cytokines and the expanding diversity of effector T cell lineages. Annu Rev Immunol (2007) 25:821-52. doi:10.1146/annurev.immunol.25.022106.141557

4. Chotirmall SH, Al-Alawi M, Mirkovic B, Lavelle G, Logan PM, Greene CM, et al. Aspergillus-associated airway disease, inflammation, and the innate immune response. Biomed Res Int (2013) 2013:723129. doi:10.1155/2013/ 723129

5. Pagano L, Caira M, Valentini CG, Posteraro B, Fianchi L. Current therapeutic approaches to fungal infections in immunocompromised hematological patients. Blood Rev (2010) 24(2):51-61. doi:10.1016/j.blre.2009. 11.003

6. Gregg KS, Kauffman CA. Invasive aspergillosis: epidemiology, clinical aspects, and treatment. Semin Respir Crit Care Med (2015) 36(5):662-72. doi:10.1055/s-0035-1562893

7. Baddley JW, Andes DR, Marr KA, Kontoyiannis DP, Alexander BD, Kauffman CA, et al. Factors associated with mortality in transplant patients with invasive aspergillosis. Clin Infect Dis (2010) 50(12):1559-67. doi:10.1086/652768

8. Barchiesi F, Mazzocato S, Mazzanti S, Gesuita R, Skrami E, Fiorentini A, et al. Invasive aspergillosis in liver transplant recipients: epidemiology, clinical characteristics, treatment, and outcomes in 116 cases. Liver Transpl (2015) 21(2):204-12. doi:10.1002/lt.24032

9. Brown GD, Denning DW, Gow NA, Levitz SM, Netea MG, White TC. Hidden killers: human fungal infections. Sci Transl Med (2012) 4(165): 165rv13. doi:10.1126/scitranslmed.3004404

10. Munoz P, Ceron I, Valerio M, Palomo J, Villa A, Eworo A, et al. Invasive aspergillosis among heart transplant recipients: a 24-year perspective. J Heart Lung Transplant (2014) 33(3):278-88. doi:10.1016/j.healun. 2013.11.003

11. Saghrouni F, Ben Youssef Y, Gheith S, Bouabid Z, Ben Abdeljelil J, Khammari I, et al. Twenty-nine cases of invasive aspergillosis in neutropenic patients. Med Mal Infect (2011) 41(12):657-62. doi:10.1016/j. medmal.2011.09.011

12. Singh N, Suarez JF, Avery R, Lass-Florl C, Geltner C, Pasqualotto AC, et al. Risk factors and outcomes in lung transplant recipients with nodular invasive pulmonary aspergillosis. J Infect (2013) 67(1):72-8. doi:10.1016/j. jinf.2013.03.013

13. Kauffman CA. Fungal infections. Proc Am Thorac Soc (2006) 3(1):35-40. doi:10.1513/pats.200510-110JH

14. Herbrecht R, Fluckiger U, Gachot B, Ribaud P, Thiebaut A, Cordonnier C. Treatment of invasive Candida and invasive Aspergillus infections in adult haematological patients. Eur J Cancer Suppl (2007) 5(2):49-59. doi:10.1016/j. ejcsup.2007.06.007

15. Arendrup MC. Update on antifungal resistance in Aspergillus and Candida. Clin Microbiol Infect (2014) 20(Suppl 6):42-8. doi:10.1111/14690691.12513

16. Nedel WL, Kontoyiannis DR, Pasqualotto AC. Aspergillosis in patients treated with monoclonal antibodies. Rev Iberoam Micol (2009) 26(3):175-83. doi:10.1016/j.riam.2009.04.001

17. Carvalho A, Cunha C, Iannitti RG, Casagrande A, Bistoni F, Aversa F, et al. Host defense pathways against fungi: the basis for vaccines and immunotherapy. Front Microbiol (2012) 3:176. doi:10.3389/fmicb.2012.00176

18. Cutler JE, Deepe GS Jr, Klein BS. Advances in combating fungal diseases: vaccines on the threshold. Nat Rev Microbiol (2007) 5(1):13-28. doi:10.1038/ nrmicro1537

19. Edwards JE Jr. Fungal cell wall vaccines: an update. J Med Microbiol (2012) 61(Pt 7):895-903. doi:10.1099/jmm.0.041665-0

20. Pikman R, Ben-Ami R. Immune modulators as adjuncts for the prevention and treatment of invasive fungal infections. Immunotherapy (2012) 4(12):1869-82. doi:10.2217/imt.12.127

21. Vecchiarelli A, Pericolini E, Gabrielli E, Pietrella D. New approaches in the development of a vaccine for mucosal candidiasis: progress and challenges. Front Microbiol (2012) 3:294. doi:10.3389/fmicb.2012.00294
22. Bozza S, Clavaud C, Giovannini G, Fontaine T, Beauvais A, Sarfati J, et al. Immune sensing of Aspergillus fumigatus proteins, glycolipids, and polysaccharides and the impact on Th immunity and vaccination. J Immunol (2009) 183(4):2407-14. doi:10.4049/jimmunol.0900961

23. Komarova BS, Orekhova MV, Tsvetkov YE, Beau R, Aimanianda V, Latge JP, et al. Synthesis of a pentasaccharide and neoglycoconjugates related to fungal alpha-(1 - >3)-glucan and their use in the generation of antibodies to trace Aspergillus fumigatus cell wall. Chemistry (2015) 21(3):1029-35. doi:10.1002/chem.201404770

24. Latge JP. 30 years of battling the cell wall. Med Mycol (2017) 55(1):4-9. doi:10.1093/mmy/myw076

25. Latge JP, Kobayashi H, Debeaupuis JP, Diaquin M, Sarfati J, Wieruszeski JM, et al. Chemical and immunological characterization of the extracellular galactomannan of Aspergillus fumigatus. Infect Immun (1994) 62(12):5424-33.

26. Latge JP, Mouyna I, Tekaia F, Beauvais A, Debeaupuis JP, Nierman W. Specific molecular features in the organization and biosynthesis of the cell wall of Aspergillus fumigatus. Med Mycol (2005) 43(Suppl 1):S15-22. doi:10.1080/13693780400029155

27. Leitao EA, Bittencourt VC, Haido RM, Valente AP, Peter-Katalinic J, Letzel $\mathrm{M}$, et al. Beta-galactofuranose-containing O-linked oligosaccharides present in the cell wall peptidogalactomannan of Aspergillus fumigatus contain immunodominant epitopes. Glycobiology (2003) 13(10):681-92. doi:10.1093/glycob/cwg089

28. Kudoh A, Okawa Y, Shibata N. Significant structural change in both O- and $\mathrm{N}$-linked carbohydrate moieties of the antigenic galactomannan from Aspergillus fumigatus grown under different culture conditions. Glycobiology (2015) 25(1):74-87. doi:10.1093/glycob/cwu091

29. Mouyna I, Fontaine T. Cell wall of aspergillus fumigatus: a dynamic structure. In: Latgé J-P, Steinbach WJ, editors. Aspergillus fumigatus and Aspergillosis. American Society of Microbiology (2009). p. 169-83.

30. Argunov DA, Krylov VB, Nifantiev NE. Convergent synthesis of isomeric heterosaccharides related to the fragments of galactomannan from Aspergillus fumigatus. Org Biomol Chem (2015) 13(11):3255-67. doi:10.1039/c4ob02634a

31. Argunov DA, Krylov VB, Nifantiev NE. The use of pyranoside-into-furanoside rearrangement and controlled $\mathrm{O}(5)->\mathrm{O}(6)$ benzoyl migration as the basis of a synthetic strategy to assemble $(1->5)$ - and $(1->6)$-linked galactofuranosyl chains. Org Lett (2016) 18(21):5504-7. doi:10.1021/acs.orglett. 6b02735

32. Krylov VB, Argunov DA, Vinnitskiy DZ, Verkhnyatskaya SA, Gerbst AG, Ustyuzhanina NE, et al. Pyranoside-into-furanoside rearrangement: new reaction in carbohydrate chemistry and its application in oligosaccharide synthesis. Chemistry (2014) 20(50):16516-22. doi:10.1002/chem. 201405083

33. Tsvetkov YE, Burg-Roderfeld M, Loers G, Arda A, Sukhova EV, Khatuntseva EA, et al. Synthesis and molecular recognition studies of the HNK-1 trisaccharide and related oligosaccharides. The specificity of monoclonal anti-HNK-1 antibodies as assessed by surface plasmon resonance and STD NMR. J Am Chem Soc (2012) 134(1):426-35. doi:10.1021/ja2083015

34. Paulovicova E, Bujdakova H, Chupacova J, Paulovicova L, Kertys P, Hrubisko M. Humoral immune responses to Candida albicans complement receptor 3-related protein in the atopic subjects with vulvovaginal candidiasis. Novel sensitive marker for Candida infection. FEMS Yeast Res (2015) 15(2):fou001. doi:10.1093/femsyr/fou001

35. Inoue $M$, Shinohara ML. Clustering of pattern recognition receptors for fungal detection. PLoS Pathog (2014) 10(2):e1003873. doi:10.1371/journal. ppat. 1003873

36. Netea MG, Ferwerda G, van der Graaf CA, Van der Meer JW, Kullberg BJ. Recognition of fungal pathogens by toll-like receptors. Curr Pharm Des (2006) 12(32):4195-201. doi:10.2174/138161206778743538

37. Rizzetto L, Giovannini G, Bromley M, Bowyer P, Romani L, Cavalieri D. Strain dependent variation of immune responses to A. fumigatus: definition of pathogenic species. PLoS One (2013) 8(2):e56651. doi:10.1371/journal. pone. 0056651

38. Loures FV, Rohm M, Lee CK, Santos E, Wang JP, Specht CA, et al. Recognition of Aspergillus fumigatus hyphae by human plasmacytoid dendritic cells is mediated by dectin-2 and results in formation of extracellular traps. PLoS Pathog (2015) 11(2):e1004643. doi:10.1371/journal.ppat. 1004643 
39. Mambula SS, Sau K, Henneke P, Golenbock DT, Levitz SM. Toll-like receptor (TLR) signaling in response to Aspergillus fumigatus. J Biol Chem (2002) 277(42):39320-6. doi:10.1074/jbc.M201683200

40. Roeder A, Kirschning CJ, Rupec RA, Schaller M, Korting HC. Toll-like receptors and innate antifungal responses. Trends Microbiol (2004) 12(1): 44-9. doi:10.1016/j.tim.2003.11.003

41. Taylor PR, Martinez-Pomares L, Stacey M, Lin HH, Brown GD, Gordon S. Macrophage receptors and immune recognition. Annu Rev Immunol (2005) 23:901-44. doi:10.1146/annurev.immunol.23.021704.115816

42. Carvalho A, Cunha C, Carotti A, Aloisi T, Guarrera O, Di Ianni M, et al. Polymorphisms in toll-like receptor genes and susceptibility to infections in allogeneic stem cell transplantation. Exp Hematol (2009) 37(9):1022-9. doi:10.1016/j.exphem.2009.06.004

43. Chai LY, Vonk AG, Kullberg BJ, Netea MG. Immune response to Aspergillus fumigatus in compromised hosts: from bedside to bench. Future Microbiol (2011) 6(1):73-83. doi:10.2217/fmb.10.158

44. Park SJ, Mehrad B. Innate immunity to Aspergillus species. Clin Microbiol Rev (2009) 22(4):535-51. doi:10.1128/CMR.00014-09

45. Sambatakou H, Pravica V, Hutchinson IV, Denning DW. Cytokine profiling of pulmonary aspergillosis. Int J Immunogenet (2006) 33(4):297-302. doi:10.1111/j.1744-313X.2006.00616.x

46. Chai LY, van de Veerdonk F, Marijnissen RJ, Cheng SC, Khoo AL, Hectors M, et al. Anti-Aspergillus human host defence relies on type $1 \mathrm{~T}$ helper (Th1), rather than type $17 \mathrm{~T}$ helper (Th17), cellular immunity. Immunology (2010) 130(1):46-54. doi:10.1111/j.1365-2567.2009.03211.x

47. Sales-Campos H, Tonani L, Cardoso CR, Kress MR. The immune interplay between the host and the pathogen in Aspergillus fumigatus lung infection. Biomed Res Int (2013) 2013:693023. doi:10.1155/2013/693023

48. Roilides E, Filioti J, Gil-Lamaignere C. Cytokines and the host defense against Aspergillus fumigatus. In: Kotb M, Calandra T, editors. Cytokines and Chemokines in Infectious Diseases Handbook. Totowa, NJ: Humana Press (2003). p. 215-26.

49. Kandalla PK, Sarrazin S, Molawi K, Berruyer C, Redelberger D, Favel A, et al. M-CSF improves protection against bacterial and fungal infections after hematopoietic stem/progenitor cell transplantation. J Exp Med (2016) 213(11):2269-79. doi:10.1084/jem.20151975

50. Kasahara S, Jhingran A, Dhingra S, Salem A, Cramer RA, Hohl TM. Role of granulocyte-macrophage colony-stimulating factor signaling in regulating neutrophil antifungal activity and the oxidative burst during respiratory fungal challenge. J Infect Dis (2016) 213(8):1289-98. doi:10.1093/ infdis/jiw054

51. Veldhoen M. Interleukin 17 is a chief orchestrator of immunity. Nat Immunol (2017) 18(6):612-21. doi:10.1038/ni.3742

52. Hybertson BM, Gao B, Bose SK, McCord JM. Oxidative stress in health and disease: the therapeutic potential of Nrf2 activation. Mol Aspects Med (2011) 32(4-6):234-46. doi:10.1016/j.mam.2011.10.006

53. Swanink CM, Meis JF, Rijs AJ, Donnelly JP, Verweij PE. Specificity of a sandwich enzyme-linked immunosorbent assay for detecting Aspergillus galactomannan. J Clin Microbiol (1997) 35(1):257-60.

54. Serrano-Gomez D, Dominguez-Soto A, Ancochea J, Jimenez-Heffernan JA, Leal JA, Corbi AL. Dendritic cell-specific intercellular adhesion molecule 3-grabbing nonintegrin mediates binding and internalization of Aspergillus fumigatus conidia by dendritic cells and macrophages. J Immunol (2004) 173(9):5635-43. doi:10.4049/jimmunol.173.9.5635

55. Barton RC. Laboratory diagnosis of invasive aspergillosis: from diagnosis to prediction of outcome. Scientifica (Cairo) (2013) 2013:459405. doi:10.1155/ 2013/459405

56. Stynen D, Sarfati J, Goris A, Prevost MC, Lesourd M, Kamphuis H, et al. Rat monoclonal antibodies against Aspergillus galactomannan. Infect Immun (1992) 60(6):2237-45.

57. Huang YT, Hung CC, Hsueh PR. Aspergillus galactomannan antigenemia in Penicilliosis marneffei. AIDS (2007) 21(14):1990-1. doi:10.1097/ QAD.0b013e3282eeb413

58. Mikulska M, Furfaro E, Del Bono V, Gualandi F, Raiola AM, Molinari MP, et al. Galactomannan testing might be useful for early diagnosis of fusariosis. Diagn Microbiol Infect Dis (2012) 72(4):367-9. doi:10.1016/j.diagmicrobio. 2011.12.009

59. Schuetz AN, Cohen C. Aspergillus immunohistochemistry of cultureprovenfungaltissueisolatesshowshigh cross-reactivity. ApplImmunohistochem Mol Morphol (2009) 17(6):524-9. doi:10.1097/PAI.0b013e3181a38e05

60. Krylov Vadim B, Paulovičová L, Paulovičová E, Tsvetkov Yury E, Nifantiev Nikolay E. Recent advances in the synthesis of fungal antigenic oligosaccharides. Pure Appl Chem (2017) 89(7):885-98. doi:10.1515/pac2016-1011

61. Casadevall A. Antibody immunity and invasive fungal infections. Infect Immun (1995) 63(11):4211-8.

62. Gronwall C, Vas J, Silverman GJ. Protective roles of natural IgM antibodies. Front Immunol (2012) 3:66. doi:10.3389/fimmu.2012.00066

63. Ehrenstein MR, Notley CA. The importance of natural IgM: scavenger, protector and regulator. Nat Rev Immunol (2010) 10(11):778-86. doi:10.1038/ nri2849

64. Gupta P, Goyal S, Kaushal M. Concomitant Aspergillus species infection and squamous cell carcinoma diagnosed on Pap Smear. Turk Patoloji Derg (2016) 32(1):54-6. doi:10.5146/tjpath.2013.01198

65. Baggish MS, Ventolini G. Vulvovaginal colonization by Aspergillus species in nonimmunocompromised women. J Gynecol Surg (2008) 24(2):55-60. doi:10.1089/gyn.2008.B-00242-1

66. Agarwal N, Seth A, Kulshrestha V, Kochar S, Kriplani A. Spontaneous vesicovaginal fistula caused by genitourinary aspergillosis. Int J Gynaecol Obstet (2009) 105(1):63-4. doi:10.1016/j.ijgo.2008.11.005

67. Ventolini G. Aspergillus and vaginal colonization. J Anc Dis Prev Rem (2014) 2:e115. doi:10.4172/2329-8731.1000e115

Conflict of Interest Statement: The authors declare that the research was conducted in the absence of any commercial or financial relationships that could be construed as a potential conflict of interest.

Copyright (1) 2017 Paulovičová, Paulovičová, Hrubiško, Krylov, Argunov and Nifantiev. This is an open-access article distributed under the terms of the Creative Commons Attribution License (CC BY). The use, distribution or reproduction in other forums is permitted, provided the original author(s) or licensor are credited and that the original publication in this journal is cited, in accordance with accepted academic practice. No use, distribution or reproduction is permitted which does not comply with these terms. 